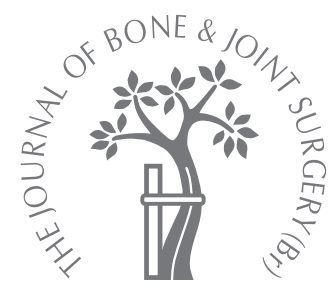

\title{
Radiological outcome analysis of transtrochanteric curved varus osteotomy for osteonecrosis of the femoral head at a mean follow-up of 12.4 years
}

\begin{abstract}
G. Zhao,
T. Yamamoto, S. Ikemura, G. Motomura, T. Mawatari, Y. Nakashima, Y. Iwamoto
\end{abstract}

From Kyushu University, Fukuoka, Japan

\footnotetext{
G. Zhao, MD, Orthopaedic Surgeon

T. Yamamoto, $\mathrm{MD}, \mathrm{PhD}$, Assistant Professor, Orthopaedic Surgeon - S. Ikemura, MD, PhD, Research Fellow,. Orthopaedic Surgeon

a. Motomura, MD, PhD, Assistant Professor, Orthopaedic Surgeon T. Mawatari, MD, PhD, Assistant Professor, Orthopaedic Surgeon Y. Nakashima, MD, PhD, Assistant Professor, Orthopaedic Surgeon Y. Iwamoto, MD, PhD, Professor, Chairman, Orthopaedic Surgeon Department of Orthopaedic Surgery, Graduate School of Medical Sciences Kyushu University, 3-1-1 Maidashi, Higashi-ku, Fukuoka 812-8582, Japan.

Correspondence should be sent to Dr T. Yamamoto; e-mail: yamataku@ortho.med.kyushuu.ac.jp
}

(C)2010 British Editorial Society of Bone and Joint Surgery doi:10.1302/0301-620X.92B6. $23621 \$ 2.00$

$J$ Bone Joint Surg $[\mathrm{Br}]$ 2010;92-B:781-6. Received 7 October 2009; Accepted after revision 15 February 2010

\begin{abstract}
We investigated the factors related to the radiological outcome of a transtrochanteric curved varus osteotomy in patients with osteonecrosis of the hip. We reviewed 73 hips in 62 patients with a mean follow-up of 12.4 years (5 to 31.1). There were 28 men and 34 women, with a mean age of 33.3 years ( 15 to 68 ) at the time of surgery. The 73 hips were divided into two groups according to their radiological findings: group 1 showed progression of collapse and/or joint-space narrowing; group 2 had neither progressive collapse nor joint-space narrowing. Both of these factors and the radiological outcomes were analysed by a stepwise discriminant analysis. A total of 12 hips were categorised as group 1 and 61 as group 2. Both the post-operative intact ratio and the localisation of the necrotic lesion correlated with the radiological outcome. The cut-off point of the postoperative intact ratio to prevent the progression of collapse was $33.6 \%$, and the cut-off point to prevent both the progression of collapse and joint-space narrowing was $41.9 \%$.

The results of this study indicate that a post-operative intact ratio of $33.0 \%$ is necessary if a satisfactory outcome is to be achieved after this varus osteotomy.
\end{abstract}

Corticosteroid administration and alcoholism have been identified as risk factors for the development of non-traumatic osteonecrosis of the femoral head. ${ }^{1}$ Osteonecrosis often leads to secondary degenerative osteoarthritis. ${ }^{2}$ Consideration of joint preservation is important in order to avoid or delay joint replacement procedures, because osteonecrosis often occurs in younger patients.

The transtrochanteric curved varus osteotomy procedure was developed as a jointpreserving operation. ${ }^{3}$ It was designed to prevent complications that may occur after a varus osteotomy, including elevation of the greater trochanter, lateral displacement of the femoral shaft with weakening of gluteus medius and minimus muscles, and leg-length discrepancy. ${ }^{4-9}$ In addition, this osteotomy is more favourable biomechanically than a conventional varus wedge osteotomy, as a wide contact area is obtained at the site of the osteotomy. Several studies have investigated the results of transtrochanteric curved varus osteotomy for osteonecrosis, reporting the good clinical and radiological outcomes. ${ }^{10-12}$ Miyanishi et $\mathrm{al}^{13}$ reported the ideal postoperative intact ratio for rotational osteotomy, however, there have been no reports assessing the factors that may correlate with the radiological outcome of the transtrochanteric curved varus osteotomy. We, therefore, assessed the relationship between specific radiological parameters and the outcome of a transtrochanteric curved varus osteotomy for osteonecrosis.

\section{Patients and Methods}

Between 1970 and 2004, transtrochanteric curved varus osteotomy was performed on 79 hips in 68 patients for the treatment of osteonecrosis, ${ }^{12}$ five patients were lost to follow-up within five years after surgery, and one underwent total hip replacement (THR) two years after surgery. Accordingly, we were able to review 73 hips in 62 patients with a minimum follow-up of five years. This study was approved by the institutional review board.

The patients included 28 men and 34 women with a mean age of 33.3 years (15 to 68 ) at the time of surgery. The mean body mass index (BMI) was $21.4 \mathrm{~kg} / \mathrm{m}^{2}$ (16.6 to 37.1). The mean follow-up was 12.4 years $(5.0$ to 31.1), with follow-up ending when the patient underwent THR.

A total of 45 patients had a bilateral procedure and all had a transtrochanteric curved varus osteotomy on one side, only 11 had the same operation on the other side. The remainder were treated by a transtrochanteric rota- 
Table I. The results of the univariate analyses between groups 1 and 2

\begin{tabular}{|c|c|c|c|}
\hline & Group 1 (12 hips) & Group 2 (61 hips) & p-values \\
\hline \multicolumn{4}{|l|}{ Gender } \\
\hline Male & 8 & 24 & 0.114 \\
\hline Female & 4 & 37 & \\
\hline Mean age in years (range) & 34.67 (18 to 51$)$ & 32.98 (15 to 68$)$ & 0.670 \\
\hline Mean body mass index $\left(\mathrm{kg} / \mathrm{m}^{2}\right)$ (range) & $23.00(19$ to 28$)$ & $21.20(16.6$ to 37.1$)$ & 0.177 \\
\hline \multicolumn{4}{|l|}{ Operated side } \\
\hline Right & 7 & 33 & 1.000 \\
\hline Left & 5 & 28 & \\
\hline \multicolumn{4}{|l|}{ Contralateral condition } \\
\hline ON*, present & 9 & 47 & 1.000 \\
\hline ON, absent & 3 & 14 & \\
\hline \multicolumn{4}{|l|}{ Contralateral treatment } \\
\hline Rotational osteotomy & 4 & 12 & \\
\hline Varus osteotomy & 3 & 19 & \\
\hline Prosthetic replacement & 2 & 6 & 0.324 \\
\hline No operation & 3 & 24 & \\
\hline \multicolumn{4}{|l|}{ The aetiology of ON } \\
\hline Steroid & 5 & 47 & \\
\hline Alcohol & 5 & 6 & 0.054 \\
\hline Trauma & 0 & 2 & \\
\hline Idiopathic & 2 & 6 & \\
\hline Mean pre-operative $\mathrm{HHS}^{\dagger}$ (range) & 53.56 (36 to 73$)$ & 61.74 (34 to 85 ) & 0.019 \\
\hline \multicolumn{4}{|l|}{ Stage } \\
\hline $3 \mathrm{~A}$ & 2 & 46 & \\
\hline 3B & 9 & 14 & 0.001 \\
\hline 4 & 1 & 1 & \\
\hline \multicolumn{4}{|l|}{ Type } \\
\hline B & 0 & 2 & \\
\hline $\mathrm{C} 1$ & 2 & 54 & 0.001 \\
\hline $\mathrm{C} 2$ & 10 & 5 & \\
\hline Mean varus angulations $\left({ }^{\circ}\right)$ (range) & $24.50(15$ to 35$)$ & $25.05(12$ to 38$)$ & 0.779 \\
\hline Mean post-operative intact ratio (\%) (range) & 34.73 (26 to 42.9$)$ & $61.83(80$ to 100$)$ & 0.001 \\
\hline
\end{tabular}

tional osteotomy in 16 patients, a bipolar hemiarthroplasty in five, THR in three, and no surgical treatment in ten (Table I).

The diagnosis of osteonecrosis of the femoral head was based on the clinical presentation and imaging studies, including plain radiographs and MRI findings. ${ }^{14}$ The aetiology of osteonecrosis involved corticosteroids in 52 hips, alcohol abuse in 11, was considered to be idiopathic in eight and the consequence of trauma in two. According to the classification of the Japanese Investigation Committee of Health and Welfare, ${ }^{15} 48$ hips were classified as stage $3 \mathrm{~A}$ (which indicates collapse of the femoral head to be $<3 \mathrm{~mm}$ ), 23 were classified as stage $3 \mathrm{~B}$ (with $3 \mathrm{~mm}$ or more of collapse), and two were classified as stage 4 (osteoarthritic change). The localisation of the necrotic lesion was type B in two hips, type C1 in 56, and type C2 in 15 (Fig. 1).

A clinical assessment was performed based on the Harris hip score (HHS). ${ }^{16}$ The following factors were investigated radiologically: the varus angle, ${ }^{12}$ which was the pre-operative neck-shaft angle minus the post-operative neck-shaft angle on the anteroposterior (AP) radiograph, the post-operative intact ratio ${ }^{12,17}$ (Fig. 2), the progression of collapse, and joint-space narrowing.

Any patient who had the potential to obtain cover of more than one-third of the intact articular surface on pre-operative AP hip radiographs in maximum abduction and thus with an intact ratio of $>30 \%$ was considered suitable for 


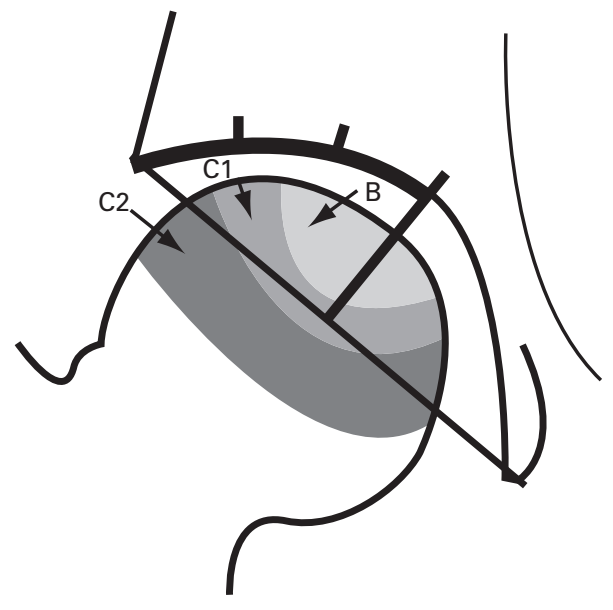

Fig. 1

Diagram of localisation of the affected necrotic lesion (according to the classification of the Japanese Investigation Committee of Health and Welfare). Type B: the necrotic area occupies the medial two-thirds or less of the region. Type $\mathrm{C} 1$ : the necrotic area occupies more than two-thirds of the region but does not extend to the acetabular edge. Type C2: the necrotic area occupies more than two-thirds of the region and extends to the acetabular edge.

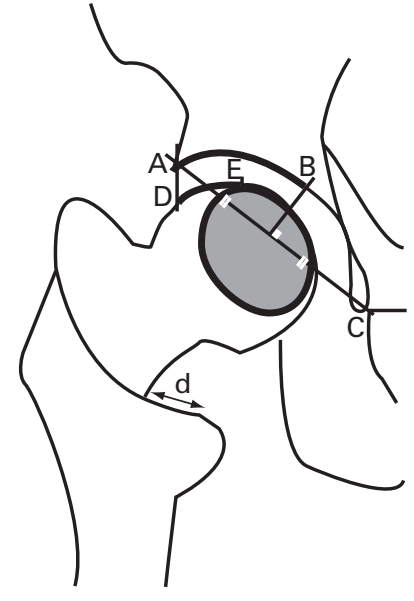

Fig. 2

Diagram of the intact ratio of the articular surface of the femoral head to the weight-bearing area of the acetabulum on post-operative anteroposterior (AP) radiographs (post-operative intact ratio). Point $B$ is determined by drawing a perpendicular line from the midpoint of $A$ (the edge of the acetabulum) and C (the lowest point of the teardrop) to the acetabular roof. Point D represents the lateral edge of the loadbearing portion. Point $E$ represents the medial edge of the intact articular surface of the femoral head. The post-operative intact ratio is expressed as $D$ to $E / A$ to $B$. The planned varus angle is confirmed during surgery by measuring the amount of displacement of the proximal femur (d), which was calculated pre-operatively.

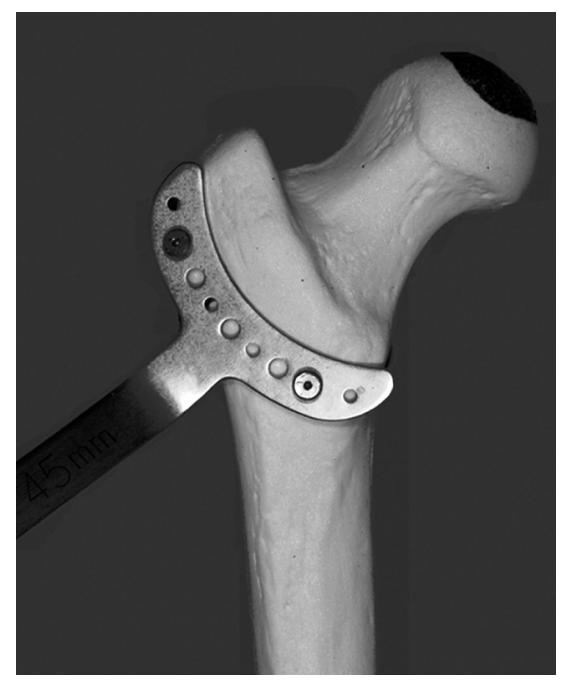

Fig. 3a

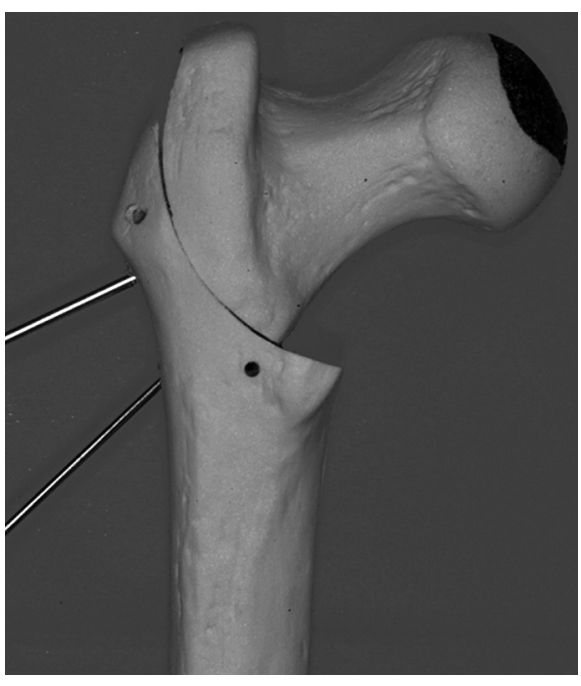

Fig. 3b

Photographs of a transtrochanteric curved varus osteotomy model, showing a) the crescentic guide is attached at least $5 \mathrm{~mm}$ lateral to the inter-trochanteric crest in order to preserve the nutrient vessels and b) after $20^{\circ}$ of varus angulation, the intact lateral surface becomes the new weight-bearing portion.

this operation. ${ }^{13}$ These radiographs were also used to predict the post-operative congruity of the hip joint. Passive abduction of the hip of $<20^{\circ}$ was considered a contra-indication for this procedure and these patients were excluded to prevent the development of an adduction contracture.
Both the surgical technique and post-operative regime have been described previously. ${ }^{11,12}$ Briefly, after the lesser trochanter and inter-trochanteric crest have been exposed along the planned osteotomy line in internal rotation, the crescentic guide is attached at least $5 \mathrm{~mm}$ lateral to the side 


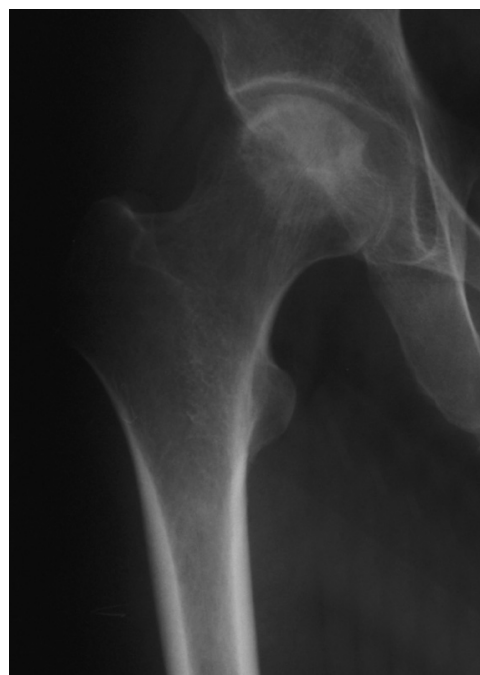

Fig. 4a

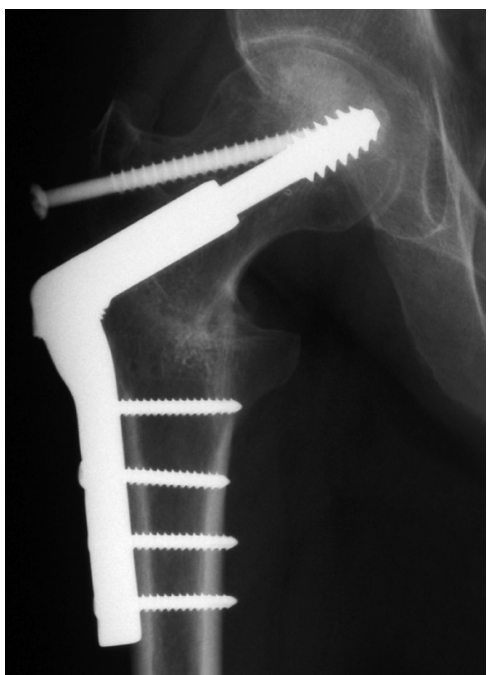

Fig. 4b

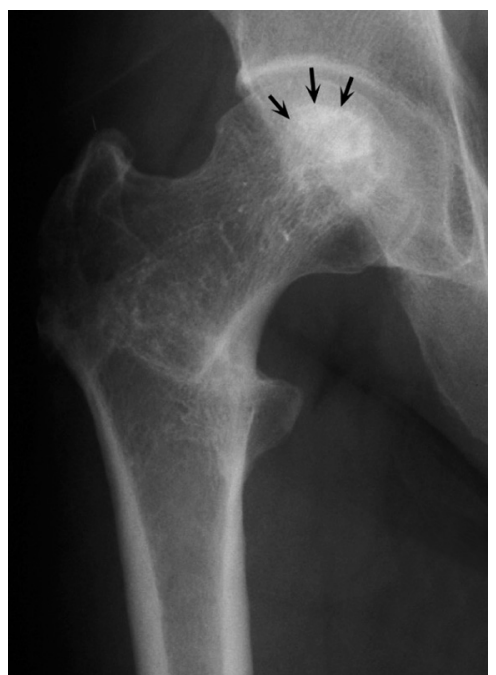

Fig.4c

Radiographs of osteonecrosis in a 39-year-old man, showing a) pre-operative radiograph, the hip was classified as stage $3 \mathrm{~A}$ and type $\mathrm{C} 1$, b) post-operative radiograph after a $20^{\circ}$ varus osteotomy, a $75 \%$ post-operative intact ratio was obtained and c) radiographs ten years after the operation with neither the progression of collapse nor any joint-space narrowing observed. The size of the necrotic area, which is surrounded by a sclerotic line, had decreased (arrows), indicating that some repair was obtained by the varus osteotomy.

of the inter-trochanteric crest to preserve the posterior retinacular artery which arises from the medial femoral circumflex artery (Fig. 3a). An inter-trochanteric curved osteotomy is made in the sagittal plane, perpendicular to the coronal plane. The proximal fragment is moved into varus (Fig. 3b) and the planned varus angle is confirmed by measuring the distance that the fragments have been moved, with the required translation having been calculated pre-operatively (Fig. 2). The osteotomy is stabilised with a large screw and then with a plate and screws (Fig. 4). Finally, achievement of the planned varus angle is confirmed with intra-operative radiographs.

The patient is permitted to start bearing weight and walking five weeks after operation. Radiologic and clinical examinations (HHS) are performed at three months, six months, and yearly thereafter.

Statistical analyses. The pre- and post-operative HHS scores were compared using the paired $t$-test. Examination of the outcome for the different types of osteonecrosis was studied using a one-way analysis of variance, with Scheffe's post hoc test with regard to the post-operative intact ratio.

The 73 hips were divided into two groups based on the findings of the post-operative radiographs (group 1: those with progression of collapse and/or joint-space narrowing; and group 2: those without either progressive collapse or joint-space narrowing). The mean values for age, BMI, preoperative HHS, amount of varus and post-operative intact ratio were compared between groups using unpaired $t$-tests. Fisher's exact probability test was used with regard to gender, operated side, stage, type, contralateral condition, treatment and aetiology of osteonecrosis.
Table II. The results of multivariate analyses using a stepwise discriminant analysis

\begin{tabular}{lll}
\hline & Wilks' $\lambda$ & p-values \\
\hline The aetiology of osteonecrosis & 0.464 & 0.07 \\
Stage & 0.457 & 0.113 \\
Type & 0.476 & 0.013 \\
Post-operative intact ratio & 0.483 & 0.004 \\
\hline
\end{tabular}

A multivariate analysis was performed using a stepwise discriminate analysis (selection $=$ stepwise, slentry $=0.2$, slstay $=0.25)$ where selection specifies the method for model selection and slentry and slstay are used to provide additional specifications for model selection. ${ }^{18}$ Survival data were calculated by a Kaplan-Meier analysis with $95 \%$ confidence intervals (CI) and survival curves between the two groups were compared using the log-rank test. All analyses were performed using the Statistical Package for Social Sciences (SPSS Inc., Chicago, Illinois). A p-value $<0.05$ was considered significant.

\section{Results}

The mean pre-operative HHS was 60.4 points (34 to 85 ), which improved to 85.7 (51 to 100$)$ at the final follow-up $(\mathrm{p}<0.001)$.

The mean post-operative intact ratio was $57.2 \%$ (27 to $100)$. The mean post-operative intact ratios were $83.4 \%$ (81.0 to 85.7 ) for type B, 61.4\% (31.1 to 100 ) for type C1, and $38.2 \%$ (26.0 to 60.0) for type $\mathrm{C} 2$. There were significant differences between type B and C2 and between type C1 and 
Table III. The results of stepwise discriminant analysis with regard to the progression of collapse

\begin{tabular}{|c|c|c|c|}
\hline & Mean (range) & Variance & Cut-off point \\
\hline \multicolumn{4}{|l|}{ Post-operative intact ratio (\%) } \\
\hline $\mathrm{n}=5$ (progression of collapse) & 31.16 (26 to 33.3 ) & 7.08 & 33.6 \\
\hline $\mathrm{n}=68$ (without progression of collapse) & 59.27 (32 to 100$)$ & 231.49 & \\
\hline Wilks' $\lambda$ & F value & p-value & \\
\hline 0.773 & 21.636 & $<0.001$ & \\
\hline Sensitivity & Specificity & Correct & \\
\hline $82.9 \%$ & $100 \%$ & $91.8 \%$ & \\
\hline
\end{tabular}

Table IV. The results of stepwise discriminant analysis with regard to the progression of collapse and joint-space narrowing

\begin{tabular}{|c|c|c|c|}
\hline & Mean (range) & Variance & Cut-off point \\
\hline \multicolumn{4}{|l|}{ Post-operative intact ratio (\%) } \\
\hline $\mathrm{n}=12$ (progression of collapse and/or joint-space narrowing) & 34.73 (26 to 42.9$)$ & 37.66 & 41.9 \\
\hline $\mathrm{n}=61$ (without progression of collapse and joint-space narrowing) & $61.83(40$ to 100$)$ & 190.79 & \\
\hline Wilks' $\lambda$ & F value & p-value & \\
\hline 0.588 & 50.115 & $<0.001$ & \\
\hline Sensitivity & Specificity & Correct & \\
\hline $88.9 \%$ & $92.1 \%$ & $89.8 \%$ & \\
\hline
\end{tabular}

$\mathrm{C} 2$ ( $\mathrm{p}<0.001$ for both). The mean pre-operative neck-shaft angle was $134^{\circ}\left(128^{\circ}\right.$ to $\left.147^{\circ}\right)$. The osteotomy resulted in a mean varus angulation of $24.9^{\circ}\left(12^{\circ}\right.$ to $\left.38^{\circ}\right)$. No increase in the varus angulations was observed on AP radiographs in any hip during the follow-up period.

Examination of the post-operative radiographs assigned 12 hips to group 1 and 61 to group 2. Data from the two groups are summarised in Table I. The mean values for the pre-operative HHS, post-operative intact ratio, stage, type and aetiology tended to influence the radiological outcome of this procedure. A multivariate analysis demonstrated significant differences in the post-operative intact ratio between groups 1 and $2(p=0.004)$ and among the types of osteonecrosis $(\mathrm{p}=0.0132)$ (Table II). Six hips in group 1 were converted to THR at a mean of nine years (5 to 26) after the operation. In four of these hips there was evidence of progressive joint-space narrowing, and two had both progressive collapse and joint-space narrowing. Of the 73 hips, $67(91.8 \%)$ had remained intact without conversion to THR at the final follow-up.

The cut-off point of the post-operative intact ratio to prevent the progression of collapse was $33.6 \%$ (sensitivity $82.9 \%$, specificity $100 \%, p=0.001$; Table III) and the cutoff point to prevent both the progression of collapse and joint-space narrowing was $41.9 \%$ (sensitivity $88.9 \%$, specificity $92.1 \%, p=0.001$; Table IV). The Kaplan-Meier survival curve is shown in Figure 5. The end point is the time of the observation of the progression of collapse.

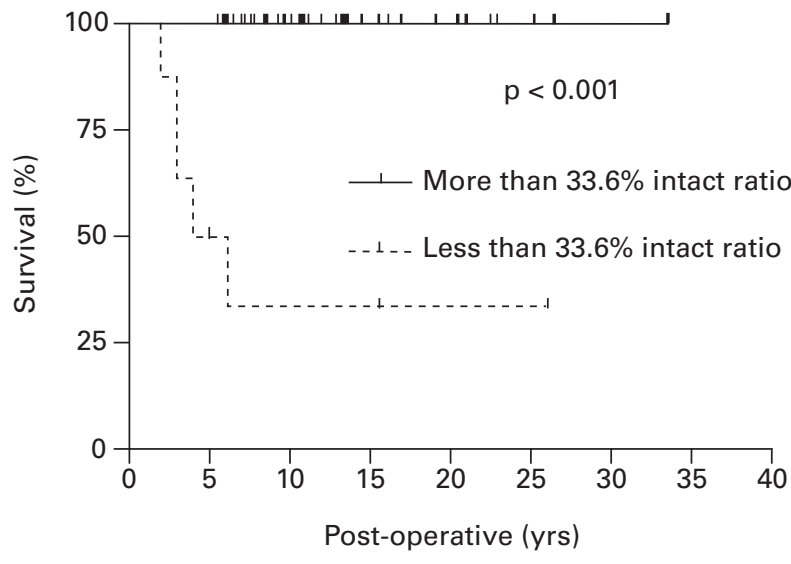

Fig. 5

Kaplan-Meier survival curve with 95\% confidence interval (Cl) (less than $33.6 \% ; 3.0$ to 17.3 years) shows the radiological survival rate according to the intact ratio. The endpoint is the time when the progression of collapse was observed. The vertical lines indicate the censored point.

\section{Discussion}

Regarding the transtrochanteric rotational osteotomy for osteonecrosis a number of authors have suggested that the post-operative intact ratio is one of the most important factors influencing the outcome. ${ }^{13,17,19-24}$ Sugioka et $\mathrm{al}^{17}$ reported a success rate of $93 \%$ after transtrochanteric 
anterior rotational osteotomy with follow-up ranging from three to 16 years when the post-operative intact ratio exceeded $36 \%$. Miyanishi et $\mathrm{al}^{13}$ reported the minimum post-operative intact ratio necessary to prevent the progressive collapse of the femoral head during the initial ten years after a transtrochanteric rotational osteotomy was $34 \%$.

The transtrochanteric curved varus osteotomy is less invasive and less technically demanding as compared with a transtrochanteric rotational osteotomy. This procedure does not require any exposure of the anterior aspect of the inter-trochanteric area. In addition, the medial femoral circumflex artery can be safely protected as the procedure does not require the dissection of the quadratus femoris which is located just above this artery. ${ }^{9,25}$ Therefore, in our institution this osteotomy has been used for patients with osteonecrosis of the hip in which the intact area is located in the lateral portion of the femoral head.

This study revealed that the minimum post-operative intact ratio necessary to prevent the progression of collapse after a transtrochanteric curved varus osteotomy was $33.6 \%$, and the minimum ratio necessary to prevent both the progression of collapse and joint-space narrowing was $41.9 \%$. The maximum varus angle that can be obtained from this osteotomy is approximately $30^{\circ}$ to $35^{\circ}$, as an excessive varus angle can cause a severe leglength discrepancy or increase varus angulations postoperatively. Ikemura et $\mathrm{al}^{12}$ reported a mean leg-length discrepancy of $13.0 \mathrm{~mm}$ with $25^{\circ}$ of varus angulation after transtrochanteric curved osteotomy and that there was a strong correlation between post-operative leg-length discrepancy and varus angulation. Thus, hips that are expected to obtain a post-operative intact ratio of at least $33 \%$ with a varus angle of less than $30^{\circ}$ are ideal for this procedure. Pre-operative measurement of the amount of displacement of the proximal femur into varus that is required is critical.

Although the aetiologies of the cases in this study suggested an association with the radiological outcome, the precise relationship remains unclear. Case-control studies, with matched aetiologies of osteonecrosis may be necessary to clarify the differences in the radiological prognosis among the various aetiologies.

The results of this study indicate that the post-operative intact ratio should be at least $33.6 \%$ in patients who undergo a transtrochanteric curved varus osteotomy for osteonecrosis.

This work was supported in part by a Grant-in-Aid from the Japan Society for the Promotion of Science (No. 21591948, 211160), Research Grant for Intractable Diseases from the Ministry of Health and Welfare of Japan, and a grant from Takeda Science Foundation.

No benefits in any form have been received or will be received from a commercial party related directly or indirectly to the subject of this article.

\section{References}

1. Assouline-Dayan Y, Chang C, Greenspan A, Shoenfeld Y, Gershwin ME. Pathogenesis and natural history of osteonecrosis. Semin Arthritis Rheum 2002;32:94-124.

2. Ohzono K, Saito M, Takaoka K, et al. Natural history of nontraumatic avascular necrosis of the femoral head. J Bone Joint Surg [Br] 1991;73-B:68-72.

3. Nishio A, Sugioka Y. A new technique of the varus osteotomy at the upper end of the femur. Orthop Trauma 1971;20:381-6.

4. Merle d'Aubigné R, Postel M, Mazabraud A, et al. Idiopathic necrosis of the femoral head in adults. J Bone Joint Surg [Br] 1965;47-B:612-33.

5. Kerboul M, Thomine J, Postel M, Merle d'Aubigné R. The conservative surgical treatment of idiopathic aseptic necrosis of the femoral head. J Bone Joint Surg $[\mathrm{Br}]$ 1974;56-B:291-6.

6. Bombelli R. Osteoarthritis of the hip: pathogenesis and consequent therapy. Berlin: Springer-Verlag, 1976.

7. Mont MA, Fairbank AC, Krackow KA, Hungerford DS. Corrective osteotomy for osteonecrosis of the femoral head. J Bone Joint Surg [Am] 1996;78-A:1032-8.

8. Ito $\mathbf{H}$, Kaneda K, Matsuno T. Osteonecrosis of the femoral head: simple varus intertrochanteric osteotomy. J Bone Joint Surg [Br] 1999;81-B:969-74.

9. Sugioka Y, Ogata K, Kitajima T, Nishio A. Transtrochanteric curved varus osteotomy in the treatment of dysplastic hip. In: Riley LH, ed. The hip. St Louis: CV Mosby Company, 1980:227-44.

10. Saito S, Ohzono K, Ono K. Joint-preserving operations for idiopathic avascular necrosis of the femoral head: results of core decompression, grafting and osteotomy. J Bone Joint Surg [Br] 1988;70-B:78-84.

11. Sakano S, Hasegawa Y, Torii Y, Kawasaki M, Ishiguro N. Curved intertrochanteric varus osteotomy for osteonecrosis of the femoral head. J Bone Joint Surg [Br] 2004;86-B:359-65.

12. Ikemura S, Yamamoto T, Jingushi S, et al. Leg-length discrepancy after transtrochanteric curved varus osteotomy for osteonecrosis of the femoral head. J Bone Joint Surg [Br] 2007;89-B:725-9.

13. Miyanishi K, Noguchi Y, Yamamoto T, et al. Prediction of the outcome of transtrochanteric rotational osteotomy for osteonecrosis of the femoral head. J Bone Joint Surg [Br] 2000;82-B:512-16.

14. Sugano N, Kubo T, Takaoka K, et al. Diagnostic criteria for non-traumatic osteonecrosis of the femoral head: a multicentre study. J Bone Joint Surg [Br] 1999;81-B:5905.

15. Sugano N, Atsumi T, Ohzono K, et al. The 2001 revised criteria for diagnosis, classification, and staging of idiopathic osteonecrosis of the femoral head. J Orthop Sci 2002;7:601-5.

16. Harris WH. Traumatic arthritis of the hip after dislocation and acetabular fractures: treatment by mold arthroplasty: an end-result study using a new method of result evaluation. J Bone Joint Surg [Am] 1969;51-A:737-55.

17. Sugioka Y, Hotokebuchi T, Tsutsui H. Transtrochanteric anterior rotational osteotomy for idiopathic and steroid-induced necrosis of the femoral head: indications and long-term results. Clin Orthop 1992;277:111-20.

18. Rencher AC, Larson SF. Bias in Wilk's A in stepwise discriminant analysis. Technometrics 1980;22:349-56.

19. Belal MA, Reichelt A. Clinical results of rotational osteotomy for treatment of avascular necrosis of the femoral head. Arch Orthop Trauma Surg 1996;115:80-4.

20. Atsumi T, Kuroki Y. Modified Sugiok's osteotomy: more than 130 degrees posterior rotation for osteonecrosis of the femoral head with large lesion. Clin Orthop 1997;334:98-107

21. Ikemura S, Yamamoto T, Jingushi S, et al. Use of a screw and plate system for a transtrochanteric anterior rotational osteotomy for ostenecrosis of the femoral head. J Orthop Sci 2007;12:260-4.

22. Sugioka Y, Yamamoto T. Transtrochanteric posterior rotational osteotomy for osteonecrosis. Clin Orthop 2008;466:1104-9.

23. Ikemura S, Yamamoto T, Nakashima Y, et al. Transtrochanteric anterior rotational osteotomy for ostenecrosis of the femoral head in patients 20 years or younger. $J$ Pediatr Orthop 2009:29:219-23.

24. Sugano N, Takaoka K, Ohzono K, et al. Rotational osteotomy for non-traumatic avascular necrosis of the femoral head. J Bone Joint Surg [Br] 1992;74-B:734-9.

25. Atsumi T, Kuroki Y. Role of impairment of blood supply of the femoral head in the pathogenesis of idiopathic osteonecrosis. Clin Orthop 1992;277:22-30. 